\title{
Interactive comment on "A fully coupled Arctic sea ice-ocean-atmosphere model (ArcIOAM v1.0) based on C-Coupler2: model description and preliminary results" by Shihe Ren et al.
}

\section{David Bailey (Referee)}

dbailey@ucar.edu

Received and published: 18 September 2020

This manuscript describes a "new" regional coupled model for the Arctic intended for short-term forecasting and shows some preliminary simulation results. My main issue with this manuscript is that I do not see the novelty here. Similar regional models such as ARCSyM (Lynch et al. 1995), RASM (Cassano, Maslowski, others), Rinke et al. 2000 have not been mentioned here. The "novel" aspect seems only to be the coupling of the MITgcm to the Polar WRF model and perhaps the new C-Coupler. I nearly recommended reject for this manuscript. It seems more like a technical report. Also, the English usage here is confusing and there are a number of grammatical errors 
that I do not have time to go into here. Here are some specific suggestions that might make this worthy of publication in GMD.

1. There needs to be more on the novel aspects here. What does this model provide specifically that previous models did not? What time scales is this intended for? Shortterm forecasting of weeks? Seasons?

2. There is no mention of the land component. Is this just the imbedded Polar WRF component? Why is this not important to the Arctic simulations?

3. The MITgcm sea ice component is quite old and simplistic. What is the albedo formulation on sea ice? What about on land? What about a sea ice thickness distribution?

4. The authors suggest that CMIP5 models represent sea ice in a simple way, but MIT$\mathrm{gcm}$ is not any more complicated. A number of CMIP5 models used the Los Alamos Sea lce Model (CICE) which is leading edge. What about CMIP6?

5. The grid staggering discussion and Figure 3 are really not necessary.

6. The case study they use is the year 2012. The boundary forcing for the atmosphere is from NCEP/NCAR re-analysis and for the ocean from the ECCO model. The sea ice extent is reasonable, but the sea ice volume is biased low compared to PIOMAS. I believe the problem here is the simplicity of the sea ice thermodynamics and lack of a subgridscale thickness distribution. I feel like the model might be tuned for 2012 and want to see how it performs for other years. Some comparison to IceSAT data would also be beneficial here.

Interactive comment on Geosci. Model Dev. Discuss., https://doi.org/10.5194/gmd-2020-95, 2020.

Printer-friendly version

Discussion paper 